\title{
BMJ Open Time from diagnosis to treatment of colorectal cancer in a South Australian clinical registry cohort: how it varies and relates to survival
}

\author{
David Roder (1) , ${ }^{1}$ Christos Stelios Karapetis, ${ }^{2}$ Ian Olver, ${ }^{1}$ Dorothy Keefe, ${ }^{3,4}$ \\ Robert Padbury, ${ }^{2,5}$ James Moore, ${ }^{4,6}$ Rohit Joshi, ${ }^{4,7}$ David Wattchow, ${ }^{2,5}$ \\ Dan L Worthley, ${ }^{8}$ Caroline Louise Miller (D) , ${ }^{9,10}$ Carol Holden (D) ${ }^{9}$ \\ Elizabeth Buckley, ${ }^{1}$ Kate Powell, ${ }^{9}$ Dianne Buranyi-Trevarton, ${ }^{3}$ Kellie Fusco, ${ }^{1}$ \\ Timothy Price ${ }^{4,11}$
}

To cite: Roder D, Karapetis CS, Olver I, et al. Time from diagnosis to treatment of colorectal cancer in a South Australian clinical registry cohort: how it varies and relates to survival. BMJ Open 2019:9:e031421. doi:10.1136/ bmjopen-2019-031421

- Prepublication history and additional material for this paper are available online. To view these files, please visit the journal online (http://dx.doi. org/10.1136/bmjopen-2019031421).

Received 07 May 2019 Revised 20 August 2019 Accepted 21 August 2019
Check for updates

(c) Author(s) (or their employer(s)) 2019. Re-use permitted under CC BY-NC. No commercial re-use. See rights and permissions. Published by BMJ.

For numbered affiliations see end of article.

Correspondence to Professor David Roder; David.Roder@unisa.edu.au

\section{ABSTRACT}

Objectives Some early studies indicated lower survival with longer time from diagnosis to cancer treatment, but others showed the reverse. We investigated time to treatment of colorectal cancer and associations with survival.

Setting and participants Clinical registry data for colorectal cancer cases diagnosed in 2000-2010 at four major public hospitals in South Australia and treated by surgery $(n=1675)$, radiotherapy $(n=616)$ and/or systemic therapy $(n=1556)$.

Design A historic cohort design, with rank-order tests for ordinal clinical and sociodemographic predictors and multiple logistic regression for comparing time from diagnosis to treatment. Unadjusted Kaplan-Meier estimates and adjusted Cox proportional hazards regression were used to investigate disease-specific survival by time to treatment. Outcome measures Time to treatment and survival from diagnosis to death from colorectal cancer.

Results Treatment (any type) commenced for $87 \%$ of surgical cases $\leq 60$ days of diagnosis, with $80 \%$ having surgery within this period. Of those receiving radiotherapy, $59 \%$ began this treatment $\leq 60$ days, and of those receiving systemic therapy, the corresponding proportion was $56 \%$. Adjusted analyses showed treatment delay $>60$ days was more likely for rectal cancers, 2006-2010 diagnoses, residents of northern than other metropolitan regions and for surgery, younger ages $<50$ years and unexpectedly, those residing closer to metropolitan services. Adjusting for clinical and sociodemographic factors, and diagnostic year, better survival occurred in $\leq 2$ years from diagnosis for time to treatment $>30$ days. Survival in the 3-10 years postdiagnosis generally did not differ by time to treatment, except for lower survival for any treatment $>90$ days for surgical cases.

Conclusions The lower survival $\leq 2$ years from diagnosis for treatment $\leq 30$ days of diagnosis is consistent with other studies attributed to preferencing more complicated cases for earlier care. Lower 3-10 years survival for surgical cases first treated $>90$ days from diagnosis is consistent with previously reported $\mathrm{U}$-shaped relationships.

\section{Strengths and limitations of this study}

- Where data were available, they were high-quality clinical registry data on diagnosis, treatment and sociodemographic covariables.

- Access to clinical service providers to assist with data interpretation.

- Precise diagnostic and treatment data were limited to $65 \%$ of cases.

- The study was observational and vulnerable to bias from practitioner choice and self-selection by patients into comparison groups.

- The ability to adjust for potential confounding was limited by the range of data available.

\section{INTRODUCTION}

Australia has a high age-standardised incidence of colorectal cancer about $87 \%$ above the world average. ${ }^{1}$ The corresponding colorectal cancer mortality rate is lower, although still about 22\% above the world average. ${ }^{1}$ Colorectal cancer is second only to prostate cancer in numbers reported annually by Australian cancer registries and second only to lung cancer in numbers of cancer deaths. $^{2}$ Age-standardised incidence has been stable, with the 2012-2014 rate being within $1 \%-2 \%$ of the rate for $1982-1984$. By comparison, the age-standardised colorectal cancer mortality rate approximately halved between these periods. ${ }^{2}$ This difference was accompanied by increases in 5-year relative survival from $52 \%$ in $1982-1986$ to $70 \%$ in 2011-2015. ${ }^{34}$

South Australian clinical registry data for colorectal cancer covering four major public hospitals showed equivalent survival and survival increases to national figures during 1980-2010, with 5-year disease-specific survival 
increasing from $48 \%$ to $63 \%$ for all stages combined. ${ }^{5}$ Stage distributions were largely unchanged, with survival increases mostly attributed to gains in stage-specific survival. ${ }^{5}$ Increases were particularly pronounced for regional stage. ${ }^{5}$ Survival increases followed increased use of adjuvant chemotherapies, particularly for regional disease. ${ }^{5}$ For rectal cancers, a significant increase in use of adjuvant radiotherapy was reported. The increases in adjuvant therapy were consistent with clinical practice guidelines. ${ }^{5}$ Chemotherapies evolved from common use of single-agent 5-fluorouracil (5-FU) to 5-FU and leucovorin. FOLFOX (leucovorin calcium, 5-FU and oxaliplatin) \pm bevacizumab and capecitabine ( \pm oxaliplatin) also became more common, along with protracted infusion of 5-FU for colon cancer, and with radiotherapy for rectal cancers. $^{5}$

While survival increases were attributed to changes in use of chemotherapy and radiotherapy, and increased surgical specialisation, ${ }^{5}$ other influences were possible. One was a change in time from diagnosis to surgical treatment. ${ }^{6}$ In the UK, treatment delays were regarded as negatively related to survival and concerns were expressed that delays may be increasing due to increased demands for colonoscopy from population screening. ${ }^{78}$ While there is limited evidence of effects of treatment delays on survival, early evidence points to a possible negative effect. ${ }^{6-8}$ Delays were also viewed negatively as a likely source of psychosocial stress. ${ }^{68}$ Cancer UK has indicated that ideally treatment would commence within 1 month of diagnosis but has recommended commencement within 2 months as a realistic target. ${ }^{9}$

Evidence of effects of time to treatment on survival has been mixed. ${ }^{10-18}$ Early studies generally pointed to lower survival with longer delay, but later studies varied with some showing better survival for longer delay, and some showing a U-shaped relationship with lower survival at both ends of the follow-up period. ${ }^{6-810-18}$ This has raised questions of whether the relationship varies with the clinical environment, with lower survival for short delays potentially reflected triaging of more aggressive cancers for early treatment in some settings. ${ }^{12} 131517$

In this study, we explore times from diagnosis to treatment, trends in these times, variations across the patient population and associations with survival. To establish a historic baseline, we analysed colorectal cancer data (2000-2010 diagnoses) from the South Australian registry data. Analyses indicated times to treatment and outcomes across the patient population at these hospitals by cancer stage, patient age, sex, socioeconomic status, service access, local health network of residence (as applying in the study period) and diagnostic epoch. We investigated whether a U-shaped relationship existed between time to treatment and survival, as reported elsewhere. ${ }^{617}$

The study was restricted to cancers where the registry had enough diagnostic detail from biopsies and other clinical sources to record a diagnosis date in advance of treatment, thereby providing an intervening period for analysis (65\% of cases). This is analogous to common registry practice of restricting survival analyses to cancers where diagnosis dates preceded dates of death. ${ }^{19}$

\section{METHODS}

A historic cohort design was used, including patients with colorectal cancer diagnosed in 2000-2010 at four major public hospitals in South Australia. Our data source was the South Australian clinical cancer registry, which is authorised under Section 64, Part 7 of the South Australian Health Care Act (2008) to support service monitoring and quality assurance. ${ }^{5}$

\section{Data sources and linkage}

Data were extracted from the clinical registry and dates and causes of death by linkage with official death records using full names, dates of birth and sex, and for additional guidance, postcode of residence, for linkage purposes.

\section{Outcome measures}

These were time in days from diagnosis to treatment start, and survival from diagnosis to death from colorectal cancer.

Dates of diagnosis and treatment were checked from available pathology and clinical reporting to optimise accuracy. Times to treatment start were calculated to treatment of 2746 colorectal cancers. ${ }^{20}$ Cases were excluded if presenting acutely with bowel obstruction or perforation and treated surgically on day 1 .

Analyses were undertaken for surgical, radiotherapy and chemotherapies respectively, and any of these treatments among surgical cases. Chemotherapies were most commonly 5-FU (Adrucil, 5-FU) given intravenously, capecitabine (Xeloda) given as a pill, oxaliplatin (Eloxatin) given intravenously, irinotecan (Camptosar) given intravenously and raltitrexed (Tomudex) given intravenously (https://www.cancer.ca/en/cancerinformation/cancer-type/colorectal/treatment/ chemotherapy/?region=on).

Cases were classified by: subsite (colon or rectum), Australian Clinico-Pathological Staging (ACPS) as A, B, C, D or unknown (UK) and grade, ${ }^{21}$ age at diagnosis, sex, area, socioeconomic status, ${ }^{22}$ geographic access to specialist radiotherapy and other specialist metropolitan services based on postcode address (coded as high, medium-high or poor), local health network of residence, as applied during the study period (ie, northern metropolitan, central metropolitan, southern metropolitan and for non-metropolitan areas to the south, country south and for non-metropolitan areas to the north, country north) and diagnostic period (2000-2005 and 20062010) (tables 1-3). Operational definitions are available in previous publications. ${ }^{521} 22$

Time from diagnosis to treatments start was categorised in days for cross-tabulations with clinical and sociodemographic variables.

\section{Statistical analysis}

The Spearman's rank test was used to analyse ordinal clinical and sociodemographic predictors; Kruskal-Wallis 


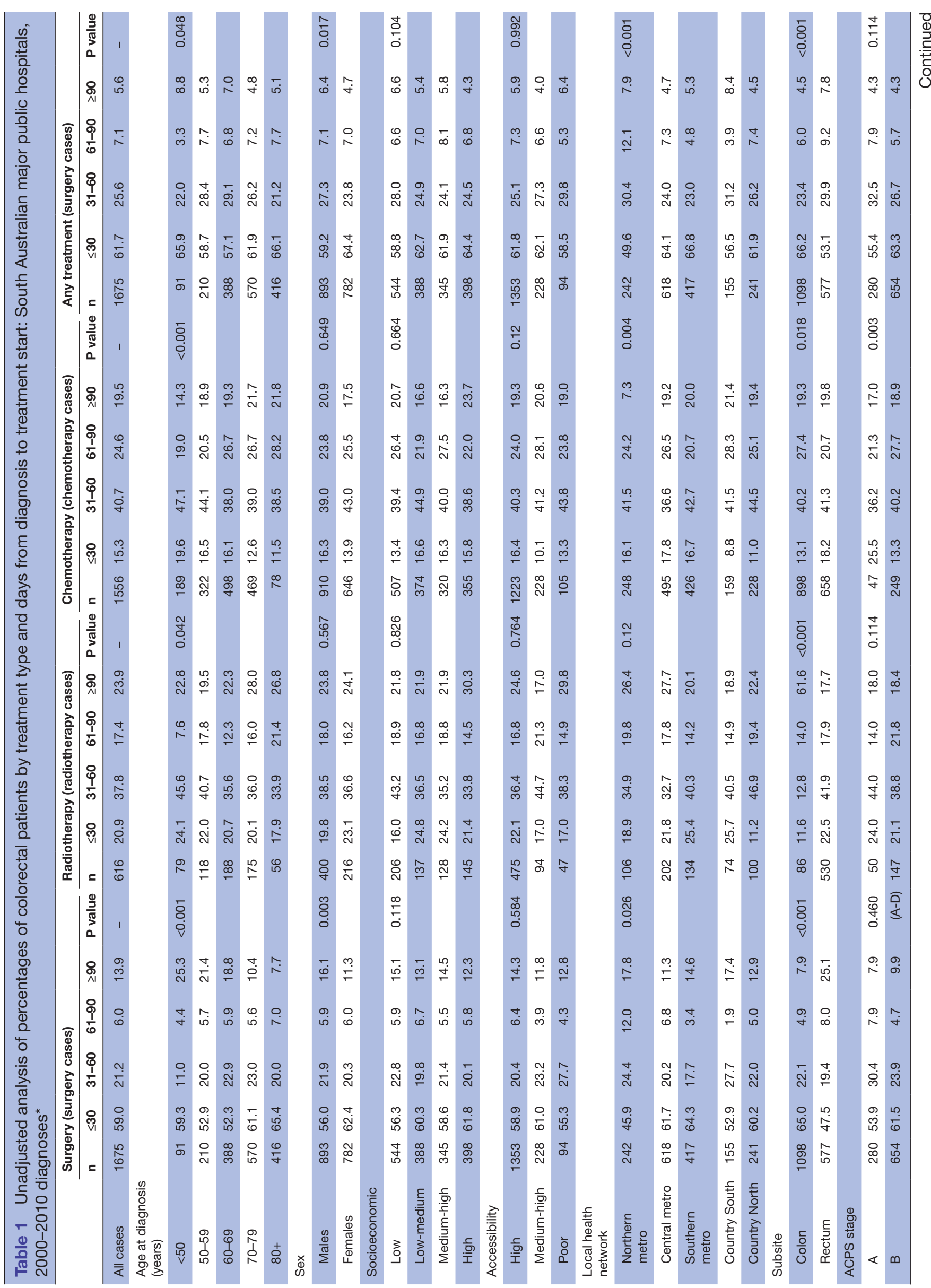






analysis of variance for multinomial predictors and MannWhitney $\mathrm{U}$ test for predictors measured on a binary scale ${ }^{2324}$ For multiple logistic regression analyses of time as the outcome variable, time was reduced to a binary outcome of ' $>30$ or 30 days' and '> $>60$ or 60 days', respectively. ${ }^{23}$ The results were expressed as relative odds (ie, ORs) with $95 \%$ confidence ranges. Disease-specific survival was analysed by time to treatment using KaplanMeier product-limit estimates (unadjusted) and Cox proportional hazards regression (adjusted for co-variables as shown in tables 2 and 3). ${ }^{23} 24$

The decision to use disease-specific survival rather than relative survival was supported by evidence of similar results from these methods in South Australia at a population level. ${ }^{5}$ Also, there were not life tables (as required for relative survival) for patients referred to specialist clinics at these hospitals who often had extensive comorbidity and other complications. ${ }^{5}$ Results are presented using conventional non-hierarchical analyses as they were similar by hospital setting without evidence of clustering.

\section{Public and patient involvement}

Registry development and workplans had substantial patient and consumer involvement through formalised cancer planning and monitoring processes. Funders reviewing workplans included the Cancer Council South Australia through the Beat Cancer Project. Specialist clinics identify topics for review, of which some are based on/prompted by the questions raised by patients.

The use of the registry was approved by the Department of Health Research Ethics Committee and University of South Australia, both with active consumer involvement, thereby providing another level of public and consumer input.

This study involved the use of routinely collected registry data specifically authorised under state law and planned by clinical experts and consumers.

Participants all attended specialised gynaecological oncology clinics with whom we work. We work with these clinics in developing consumer messages for distribution to their patients and other relevant stakeholder groups.

\section{RESULTS}

\section{Time from diagnosis to treatment start (colorectal)}

Unadjusted analyses: time from diagnosis to treatment start.

Results are presented in table 1 by treatment type.

Surgery: the proportion of surgical cases receiving surgery $\leq 60$ days of diagnosis was $80 \%$ (59\% $\leq 30$ days). Time to first surgical treatment was associated with: (a) age at diagnosis $(\mathrm{p}<0.001)$ - shorter time for older patients; (b) sex ( $\mathrm{p}=0.003)$ - shorter time for females; (c) local health network of residence $(\mathrm{p}=0.026)$-longer time for northern metropolitan; (d) tumour subsite $(\mathrm{p}<0.001)$-longer time for rectum and (e) diagnostic period $(p<0.001)$-longer time for 2006-2010. Significant associations were not found for other characteristics $(\mathrm{p} \geq 0.118)$. 
Table 2 Adjusted analysis of relative odds ( $95 \% \mathrm{CLs}$ ) of treatment for colorectal cancer starting $>30$ days of diagnosis by treatment type, stage and socioeconomic factors: South Australian major public hospitals, 2000-2010 diagnoses*

\begin{tabular}{|c|c|c|c|c|c|c|c|c|}
\hline & \multicolumn{2}{|c|}{ Surgery (surgery cases) } & \multicolumn{2}{|c|}{$\begin{array}{l}\text { Radiotherapy (radiotherapy } \\
\text { cases) }\end{array}$} & \multicolumn{3}{|c|}{ Chemotherapy (chemotherapy cases) } & $\begin{array}{l}\begin{array}{l}\text { Any treatment } \\
\text { (surgery cases) }\end{array} \\
\text { RO }(95 \% \mathrm{CLs}) \\
\end{array}$ \\
\hline \multicolumn{9}{|l|}{ Age at diagnosis (years) } \\
\hline $50-59$ & 210 & $1.15(0.68$ to 1.95$)$ & 118 & $1.06(0.52$ to 2.15$)$ & 322 & $1.18(0.71$ to 1.94$)$ & 210 & $1.20(0.70$ to 2.05$)$ \\
\hline $60-69$ & 388 & $1.16(0.71$ to 1.90$)$ & 188 & $1.16(0.60$ to 2.25$)$ & 498 & 1.25 (0.79 to 2.00$)$ & 388 & 1.26 (0.76 to 2.08$)$ \\
\hline \multicolumn{9}{|l|}{ Sex } \\
\hline Male (ref.) & 893 & 1.00 & 400 & 1.00 & 910 & 1.00 & 893 & 1.00 \\
\hline Female & 782 & 0.85 (0.69 to 1.05$)$ & 216 & $0.72(0.47$ to 1.11$)$ & 646 & $1.08(0.80$ to 1.47$)$ & 782 & $0.88(0.72$ to 1.09$)$ \\
\hline \multicolumn{9}{|l|}{ Socioeconomic } \\
\hline \multicolumn{9}{|l|}{ Accessibility } \\
\hline High (ref.) & 1353 & 1.00 & 475 & 1.00 & 1223 & 1.00 & 1353 & 1.00 \\
\hline Medium-high & 228 & $0.62(0.36$ to 1.08$)$ & 94 & $1.28(0.45$ to 3.65$)$ & 228 & $0.78(0.30$ to 2.00$)$ & 228 & $0.75(0.43$ to 1.31$)$ \\
\hline Poor & 94 & 0.83 (0.45 to 1.52$)$ & 47 & 1.14 (0.36 to 3.58$)$ & 105 & $0.60(0.23$ to 1.57$)$ & 94 & 0.89 (0.49 to 1.63$)$ \\
\hline \multicolumn{9}{|l|}{ Local health network } \\
\hline Northern metro (ref.) & 242 & 1.00 & 106 & 1.00 & 248 & 1.00 & 242 & 1.00 \\
\hline Central metro & 618 & 0.55 (0.39 to 0.76$)$ & 202 & $0.90(0.47$ to 1.72$)$ & 495 & 0.99 (0.62 to 1.57$)$ & 618 & $0.56(0.40$ to 0.78$)$ \\
\hline Southern metro & 417 & $0.44(0.31$ to 0.63$)$ & 134 & $0.68(0.35$ to 1.33$)$ & 426 & $0.84(0.52$ to 1.35$)$ & 417 & $0.44(0.30$ to 0.63$)$ \\
\hline Country South & 155 & $0.86(0.51$ to 1.43$)$ & 74 & $0.52(0.20$ to 1.38$)$ & 159 & 2.40 (0.90 to 6.39$)$ & 155 & 0.78 (0.47 to 1.30$)$ \\
\hline B & 654 & 0.87 (0.64 to 1.17$)$ & 147 & 1.03 (0.46 to 2.28$)$ & 249 & 1.78 (0.81 to 3.90$)$ & 654 & 0.80 (0.59 to 1.08$)$ \\
\hline C & 412 & $0.99(0.72$ to 1.37$)$ & 231 & 1.56 (0.72 to 3.38$)$ & 696 & 3.93 (1.85 to 8.36$)$ & 412 & 0.89 (0.65 to 1.23$)$ \\
\hline D & 279 & $0.65(0.45$ to 0.93$)$ & 162 & $0.71(0.33$ to 1.55$)$ & 516 & $0.83(0.40$ to 1.71$)$ & 279 & 0.56 (0.38 to 0.80$)$ \\
\hline UK & 50 & 0.67 (0.31 to 1.48 ) & 26 & $0.93(0.28$ to 3.06$)$ & 48 & 0.84 (0.27 to 2.62$)$ & 50 & 0.65 (0.33 to 1.25$)$ \\
\hline \multicolumn{9}{|l|}{ Grade } \\
\hline Well diff. (ref.) & 58 & 1.00 & 25 & 1.00 & 37 & 1.00 & 58 & 1.00 \\
\hline Mod diff. & 1212 & $0.68(0.39$ to 1.20$)$ & 429 & 1.34 (0.50 to 3.58$)$ & 1054 & 1.18 (0.43 to 3.22$)$ & 1212 & 0.72 (0.42 to 1.25$)$ \\
\hline Poorly undiff. & 285 & $0.47(0.25$ to 0.87$)$ & 99 & 0.87 (0.62 to 5.67$)$ & 309 & 1.28 (0.45 to 3.68$)$ & 285 & $0.52(0.28$ to 0.95$)$ \\
\hline UK & 120 & $1.48(0.75$ to 2.95$)$ & 63 & 1.02 (0.33 to 3.12$)$ & 156 & 0.41 (0.14 to 1.17$)$ & 120 & $1.44(0.74$ to 2.81$)$ \\
\hline \multicolumn{9}{|l|}{ Diagnosis year } \\
\hline 2000-2005 & 869 & 1.00 & 335 & 1.00 & 782 & 1.00 & 869 & 1.00 \\
\hline 2006-2010 & 806 & $1.82(1.48$ to 2.24$)$ & 281 & $1.48(0.97$ to 2.26$)$ & 774 & 0.65 (0.48 to 0.89$)$ & 806 & 1.86 (1.51 to 2.29$)$ \\
\hline
\end{tabular}

*Derived from multivariate logistic regression (see 'Methods')

ACPS, Australian Clinico-Pathological Staging; CLs, confidence limits; diff., differentiated; ref., reference; RO, relative odds; UK, unknown; undiff., undifferentiated.

Radiotherapy: the proportion receiving radiotherapy whose treatment started $\leq 60$ days was $59 \%(21 \% \leq 30$ days). Time to radiotherapy was associated with: (a) age at diagnosis $(\mathrm{p}=0.042)$ - longer time for older patients and (b) tumour subsite $(\mathrm{p}<0.001)$ - shorter time for rectum (note: radiotherapy was uncommon for colonic cancers). Significant associations were not found for other characteristics $(\mathrm{p} \geq 0.114)$.

Chemotherapy: the proportion receiving chemotherapy whose treatment started $\leq 60$ days was $56 \% \quad(15 \% \leq 30$ 
Table 3 Adjusted analysis of relative odds ( $95 \% \mathrm{CLs}$ ) of treatment for colorectal cancer starting $>60$ days of diagnosis by treatment type, stage and sociodemographic factors: South Australian major public hospitals, 2000-2010 diagnoses*

\begin{tabular}{|c|c|c|c|c|c|c|c|c|}
\hline & \multicolumn{2}{|c|}{ Surgery (surgery cases) } & \multicolumn{2}{|c|}{$\begin{array}{l}\text { Radiotherapy (radiotherapy } \\
\text { cases) }\end{array}$} & \multicolumn{2}{|c|}{$\begin{array}{l}\text { Chemotherapy (chemotherapy } \\
\text { cases) }\end{array}$} & \multicolumn{2}{|c|}{$\begin{array}{l}\text { Any treatment } \\
\text { (surgery cases) }\end{array}$} \\
\hline \multicolumn{9}{|l|}{ Age at diagnosis (years) } \\
\hline $50-59$ & 210 & 0.79 (0.94 to 1.42$)$ & 118 & 1.54 (0.80 to 2.99$)$ & 322 & 1.31 (0.89 to 1.94$)$ & 210 & 1.00 (0.54 to 2.27 ) \\
\hline $60-69$ & 388 & 0.73 (0.42 to 1.27$)$ & 188 & 2.22 (1.20 to 4.09 ) & 498 & $1.72(1.20$ to 2.47$)$ & 388 & 1.11 (0.54 to 2.27 ) \\
\hline \multicolumn{9}{|l|}{ Sex } \\
\hline Male (ref.) & 893 & 1.00 & 400 & 1.00 & 910 & 1.00 & 893 & 1.00 \\
\hline Female & 782 & 0.79 (0.61 to 1.04$)$ & 216 & 0.93 (0.64 to 1.35 ) & 646 & $0.93(0.75$ to 1.15$)$ & 782 & 0.89 (0.66 to 1.20$)$ \\
\hline \multicolumn{9}{|l|}{ Socioeconomic } \\
\hline \multicolumn{9}{|l|}{ Accessibility } \\
\hline High (ref.) & 1353 & 1.00 & 475 & 1.00 & 1223 & 1.00 & 1353 & 1.00 \\
\hline Medium-high & 228 & 0.37 (0.18 to 0.74$)$ & 94 & 1.36 (0.54 to 3.39$)$ & 228 & 1.23 (0.71 to 2.12 ) & 228 & 0.47 (0.21 to 1.06$)$ \\
\hline Poor & 94 & 0.40 (0.18 to 0.89$)$ & 47 & 1.50 (0.57 to 3.95$)$ & 105 & 0.92 (0.50 to 1.69 ) & 94 & 0.55 (0.23 to 1.35$)$ \\
\hline \multicolumn{9}{|l|}{ Local health network } \\
\hline Northern metro (ref.) & 242 & 1.00 & 106 & 1.00 & 248 & 1.00 & 242 & 1.00 \\
\hline Central metro & 618 & 0.58 (0.39 to 0.86$)$ & 202 & 0.84 (0.49 to 1.44$)$ & 495 & 1.24 (0.89 to 1.74$)$ & 618 & 0.56 (0.36 to 0.86$)$ \\
\hline Southern metro & 417 & 0.51 (0.33 to 0.78 ) & 134 & 0.56 (0.31 to 1.00$)$ & 426 & 0.95 (0.67 to 1.34$)$ & 417 & 0.42 (0.26 to 0.69$)$ \\
\hline Country South & 155 & 0.80 (0.44 to 1.48$)$ & 74 & 0.43 (0.18 to 1.02$)$ & 159 & 1.16 (0.66 to 2.04$)$ & 155 & 0.80 (0.40 to 1.59$)$ \\
\hline Country North & 241 & 1.24 (0.59 to 2.59$)$ & 100 & 0.56 (0.21 to 1.50$)$ & 228 & 1.02 (0.56 to 1.86$)$ & 241 & 0.97 (0.42 to 2.25$)$ \\
\hline B & 654 & 1.21 (0.80 to 1.82$)$ & 147 & 1.28 (0.62 to 2.64 ) & 249 & 1.24 (0.64 to 2.40$)$ & 654 & 0.88 (0.56 to 1.39 ) \\
\hline C & 412 & 2.32 (1.54 to 3.50$)$ & 231 & 1.73 (0.87 to 3.43 ) & 696 & 1.21 (0.65 to 2.26 ) & 412 & 1.39 (0.88 to 2.19$)$ \\
\hline D & 279 & 1.76 (1.11 to 2.78 ) & 162 & 1.37 (0.67 to 2.82 ) & 516 & 1.01 (0.53 to 1.90$)$ & 279 & 1.19 (0.71 to 1.99$)$ \\
\hline UK & 50 & 1.43 (0.59 to 3.51$)$ & 26 & 0.38 (0.10 to 1.54$)$ & 48 & 0.97 (0.35 to 2.68$)$ & 50 & 1.46 (0.63 to 3.37$)$ \\
\hline \multicolumn{9}{|l|}{ Grade } \\
\hline Well diff. (ref.) & 58 & 1.00 & 25 & 1.00 & 37 & 1.00 & 58 & 1.00 \\
\hline Mod diff. & 1212 & 0.51 (0.27 to 0.98$)$ & 429 & 0.98 (0.40 to 2.42 ) & 1054 & 1.08 (0.54 to 2.19$)$ & 1212 & 0.52 (0.23 to 1.03$)$ \\
\hline Poorly/undiff. & 285 & 0.38 (0.18 to 0.79$)$ & 99 & 1.18 (0.44 to 3.14$)$ & 309 & 1.10 (0.53 to 2.29$)$ & 285 & 0.43 (0.20 to 0.93$)$ \\
\hline UK & 120 & 1.09 (0.51 to 2.37$)$ & 63 & 0.66 (0.23 to 1.87$)$ & (156) & 0.58 (0.27 to 1.27$)$ & 120 & 0.99 (0.44 to 2.25$)$ \\
\hline \multicolumn{9}{|l|}{ Diagnostic year } \\
\hline 2000-2005 & 869 & 1.00 & 335 & 1.00 & 782 & 1.00 & 869 & 1.00 \\
\hline 2006-2010 & 806 & 1.56 (1.20 to 2.03$)$ & 281 & 0.91 (0.64 to 1.30$)$ & 774 & 1.65 (1.33 to 2.03$)$ & 806 & 1.59 (1.18 to 2.15$)$ \\
\hline
\end{tabular}

*`Derived from multivariate logistic regression (see 'Methods').

ACPS, Australian Clinico-Pathological Staging; CLs, confidence limits; diff., differentiated; ref., reference; RO, relative odds; UK, unknown; undiff., undifferentiated.

days). Time to chemotherapy was associated with: (a) age at diagnosis $(\mathrm{p}<0.001)$-longer time for older patients; (b) local health network of residence $(\mathrm{p}=0.004)-$ shorter time for northern metropolitan; (c) tumour subsite $(\mathrm{p}=0.018)$ - shorter time for rectum; (d) stage
( $\mathrm{p}=0.003)$ - shorter time for stages A and D (note: chemotherapy was uncommon for stage A) and (e) diagnostic period $(p<0.001)$-longer time for 2006-2010. Significant associations were not found by other characteristics $(\mathrm{p} \geq 0.120)$. 
Any treatment (surgical cases): The proportion receiving any treatment who did so starting $\leq 60$ days of diagnosis was $87 \%(62 \% \leq 30$ days). Time to any treatment was associated with: (a) age at diagnosis $(\mathrm{p}=0.048)$-although a clear age gradient was not evident; (b) sex $(p=0.017)$ shorter time for females; (c) local health network of residence $(p<0.001)$-longer time for the northern metropolitan area; $(d)$ tumour subsite $(p<0.001)$-longer time for rectum and (e) diagnostic period $(\mathrm{p}<0.001)$ longer time for 2006-2010. Significant associations were not found for other characteristics $(\mathrm{p} \geq 0.104)$.

Adjusted analyses: Predictors of treatment start $>30$ days from diagnosis.

Results are presented in table 2 by treatment type.

Surgery: significant predictors of time to surgical treatment $>30$ days included: (a) local health network of residence-relative odds ( $\mathrm{RO}$ ) of 0.55 (0.39 to 0.76 ) for metropolitan central and 0.44 (0.31 to 0.63 ) for metropolitan southern compared with metropolitan northern; (b) tumour site- $\mathrm{RO}$ for rectum of 2.07 (1.66 to 2.57); (c) tumour stage- $\mathrm{RO}$ of 0.65 (0.45 to 0.93 ) for stage $\mathrm{D}$ (distant metastasis) compared with stage A; (d) gradeRO for high grade (poorly differentiated) at 0.47 (0.25 to 0.87 ) compared with low grade and (e) diagnostic period-RO of 1.82 (1.48 to 2.24) for 2006-2010.

Radiotherapy: only tumour site was predictive of time to radiotherapy start $>30$ days- $\mathrm{RO}$ of 0.40 (0.19 to 0.83 ) for rectum (note: radiotherapy was much less common for colonic than rectal cancers). ${ }^{5}$

Chemotherapy: significant predictors of time to chemotherapy treatment start $>30$ days included: (a) tumour site-RO for rectum of 0.65 (0.48 to 0.89); (b) tumour stage-RO for stage $\mathrm{C}$ of 3.93 (1.85 to 8.36) and (c) diagnostic period-RO of 0.65 (0.48 to 0.89) for 2006-2010.

Any treatment (surgical cases): significant predictors of time to start of any treatment $>30$ days included: (a) local health network of residence- $\mathrm{RO}$ of 0.56 (0.40 to 0.78 ) for metropolitan central and 0.44 (0.30 to 0.63$)$ for metropolitan southern compared with metropolitan northern; (b) tumour site- $\mathrm{RO}$ of 1.76 (1.41 to 2.19) for rectum; (c) tumour stage- $\mathrm{RO}$ of 0.56 (0.38 to 0.80 ) for stage $\mathrm{D}$ compared with stage A; (d) grade- $\mathrm{RO}$ of 0.52 (0.28 to 0.95 ) for high compared with low grade and (e) diagnostic period-RO of 1.86 (1.51 to 2.29) for 2006-2010.

Supplementary analyses with tumour stage classified as stage $D$ versus $A-C$ : $\mathrm{RO}$ for surgery start $>30$ days was lower for stage $\mathrm{D}$ for surgery at 0.69 (0.51 to 0.92$)$, radiotherapy at $0.56(0.35$ to 0.88$)$, chemotherapy at $0.30(0.22$ to 0.41$)$ and any treatment (surgical cases) at 0.64 (0.47 to 0.86 ). The RO for chemotherapy treatment start $>30$ days for stage D versus A-C was 0.45 (0.30 to 0.67 ) for 2000-2005 compared with 0.16 (0.10 to 0.27) for 2006-2010.

Adjusted analyses: predictors of treatment start exceeding $>60$ days.

Results are presented in table 3 by treatment type.

Surgery: predictors of time to surgery $>60$ days for surgical cases included: (a) age at diagnosis- $\mathrm{RO}$ of 0.50 (0.29 to 0.85$)$ for $70-79$ and 0.48 ( 0.27 to 0.85 ) for $80+$ compared with $<50$ years ; (b) service accessibility- $\mathrm{RO}$ of 0.37 ( 0.18 to 0.74 ) for medium-high and 0.40 ( 0.18 to 0.89 ) for poor compared with high metropolitan service accessibility; (c) local health network of residence- $\mathrm{RO}$ of 0.58 (0.39 to 0.86 ) for metropolitan central and 0.51 (0.33 to 0.78 ) for metropolitan south compared with metropolitan north; (d) tumour site-RO for rectum of 3.39 (2.59 to 4.42); (e) tumour stage- $\mathrm{RO}$ of 2.32 (1.54 to 3.50) for stage $\mathrm{C}$ and 1.76 (1.11 to 2.78) for stage $\mathrm{D}$ compared with stage A; (f) grade- RO of 0.51 ( 0.27 to 0.98 ) for intermediate and 0.38 (0.18 to 0.79 ) for high compared with low grade and $(\mathrm{g})$ diagnostic period-RO of 1.56 (1.20 to 2.03) for 2006-2010.

Radiotherapy: predictors of time to radiotherapy start $>60$ days for cases treated by radiotherapy included: (a) older age at diagnosis-compared with age $<50$ years, RO of 2.22 (1.20 to 4.09) for 60-69 years, 2.00 (1.08 to 3.71) for 70-79 years and 2.30 (1.04 to 5.08 ) for $80+$ years and (b) tumour site-RO lower at 0.18 (0.11 to 0.32 ) for rectum (note: radiotherapy was uncommon for colonic cases).

Chemotherapy: predictors of time to chemotherapy treatment start $>60$ days for cases treated by chemotherapy included: (a) older age at diagnosis-compared with under 50 years, RO of 1.72 (1.20 to 2.47) for 60-69 years, 1.83 (1.27 to 2.64) for 70-79 years and 2.08 (1.19 to 3.63) for $80+$ years and (b) tumour subsite- $\mathrm{RO}$ for rectum of 0.78 (0.63 to 0.97 ) and (c) diagnostic period-RO higher at 1.65 (1.33 to 2.03) for 2006-2010.

Any treatment (surgical cases): predictors of time to start of any treatment $>60$ days included: (a) local health network of residence- $-\mathrm{RO}$ at 0.56 (0.36 to 0.86 ) for metropolitan central and 0.42 (0.26 to 0.69 ) for metropolitan south compared with metropolitan north; (d) tumour site$\mathrm{RO}$ for rectum at 1.82 (1.34 to 2.46); (d) grade-RO of 0.43 (0.20 to 0.93 ) for high compared with low grade and (e) diagnostic period-RO of 1.59 (1.18 to 2.15) for 2006-2010.

Supplementary analyses with tumour stage classified as stage $D$ versus $A-C$ : the $\mathrm{RO}$ for surgery start $>60$ days did not vary, with $\mathrm{RO}$ for stage $\mathrm{D}$ of 1.18 (0.84 to 1.66) for surgery, 0.92 ( 0.61 to 1.38 ) for radiotherapy, 0.83 (0.66 to 1.31 ) for chemotherapy and 1.10 (0.74 to 1.64$)$ for any treatment (surgical cases).

\section{Time from diagnosis to treatment start by subsite (colon and rectum)}

Colon

Results are presented in online supplementary tables s1 and s2.

- Predictors of time to treatment start $>30$ days in adjusted analysis included: (a) for surgery: age 60-69 years compared with $<50$ years; northern metropolitan compared with central metropolitan and southern metropolitan; stage A compared with stages B and D and diagnosis in 2006-2010; (b) for radiotherapy: no significant predictors (small numbers); (c) for chemotherapy: diagnosis in 2006-2010; (d) for any treatment 
(surgical cases): northern metropolitan compared with central metropolitan and southern metropolitan areas; stage A compared with stages $\mathrm{B}$ and $\mathrm{D}$ and diagnosis in 2006-2010.

- Predictors of time to treatment start of $>60$ days in adjusted analysis included: (a) for surgery: northern metropolitan compared with central and southern metropolitan areas; and more advanced stages $\mathrm{C}$ and D compared with stage A; (b) for radiotherapy: no significant predictors (small numbers); (c) for chemotherapy: diagnosis in 2006-2010 and (d) for any treatment (surgical cases): northern metropolitan compared with central and southern metropolitan areas.

Rectum

Results are presented in online supplementary tables s3 \& s4.

- Predictors of time to treatment start of $>30$ days in adjusted analysis included: (a) for surgery: age $70+$ compared with $<50$ years; northern metropolitan compared with central and southern metropolitan areas and diagnosis in 2006-2010; (b) for radiotherapy: low compared with medium-high socioeconomic status; and diagnosis in 2006-2010; (c) for chemotherapy: stage $\mathrm{C}$ and (d) for any treatment (surgical cases): northern metropolitan compared with southern metropolitan; and diagnosis in 2006-2010.

- Predictors of time to treatment start of $>60$ days in adjusted analysis included: (a) for surgery: younger age $<50$ compared with $70+$ years; high service accessibility; northern metropolitan compared with central and southern metropolitan areas and stage $\mathrm{C}$ compared with stage $\mathrm{A}$; better differentiation and diagnosis in 2006-2010; (b) for radiotherapy: aged $>50$ years; (c) for chemotherapy: aged $>50$ years; central metropolitan compared with northern metropolitan area and stage $\mathrm{C}$ and (d) for any treatment (surgical cases): low compared with higher grade lesions; and diagnosis in 2006-2010.

\section{Survival by time from diagnosis to treatment start}

Unadjusted analysis

Results are present in table 4.

Surgical treatment: compared with time to initial surgery $>30$ days, survival was lowest in the first 2 years from diagnosis when time to initial surgery was $\leq 30$ days, but changed with further follow-up, such that by 10 years from diagnosis, survival was lower when time to initial surgery was $>90$ days compared with $\leq 30$ days $(\mathrm{p}=0.017)$.

Radiotherapy: survival was lowest in the first year when time to radiotherapy start was $\leq 30$ days and reached statistical significance compared with a time of 61-90 days $(\mathrm{p}=0.009)$, but not with 31-60 days $(\mathrm{p}=0.295)$ or $>90$ days $(\mathrm{p}=0.280)$. After the first year of follow-up, survival was lowest for $>90$ days.

Chemotherapy: the survival pattern varied, with time to treatment $\leq 30$ days having the lowest survival at each follow-up time.

Any treatment (surgical cases): compared with time to initial treatment $>30$ days, survival was lowest in the first 2 years from diagnosis when time to initial surgery was $\leq 30$ days, but changed with further follow-up, such that

\begin{tabular}{|c|c|c|c|c|c|c|c|c|}
\hline \multirow{2}{*}{$\begin{array}{l}\text { Specified } \\
\text { treatment }\end{array}$} & \multirow[b]{2}{*}{ Time (days) } & \multirow{2}{*}{$\begin{array}{l}\text { Numbers } \\
\text { of cases }\end{array}$} & \multicolumn{6}{|c|}{ Follow-up time from diagnosis (years) } \\
\hline & & & 1 & 2 & 3 & 4 & 5 & 10 \\
\hline \multirow{4}{*}{$\begin{array}{l}\text { Surgical treatment } \\
\text { (surgery cases) }\end{array}$} & $\leq 30$ & 988 & $85.4 \pm 1.2$ & $78.2 \pm 1.5$ & $72.9 \pm 1.5$ & $69.8 \pm 1.6$ & $67.5 \pm 1.7$ & $63.3 \pm 2.0$ \\
\hline & $31-60$ & 355 & $93.1 \pm 1.6$ & $89.9 \pm 1.9$ & $84.7 \pm 2.2$ & $81.9 \pm 2.4$ & $79.7 \pm 2.5$ & $75.9 \pm 2.9$ \\
\hline & $61-90$ & 100 & $92.9 \pm 3.7$ & $84.1 \pm 4.6$ & $77.5 \pm 5.3$ & $74.6 \pm 5.5$ & $72.6 \pm 5.8$ & $57.7 \pm 9.0$ \\
\hline & $>90$ & 232 & $92.6 \pm 2.2$ & $82.4 \pm 2.9$ & $73.9 \pm 3.2$ & $67.4 \pm 3.5$ & $67.8 \pm 3.7$ & $50.4 \pm 5.0$ \\
\hline \multirow{4}{*}{$\begin{array}{l}\text { Radiotherapy } \\
\text { (radiotherapy } \\
\text { cases) }\end{array}$} & $\leq 30$ & 129 & $82.0 \pm 4.0$ & $70.0 \pm 4.5$ & $62.4 \pm 4.7$ & $58.0 \pm 4.7$ & $53.1 \pm 4.8$ & $44.4 \pm 5.5$ \\
\hline & $31-60$ & 233 & $87.0 \pm 2.6$ & $77.8 \pm 3.0$ & $68.2 \pm 3.4$ & $64.4 \pm 3.5$ & $61.3 \pm 3.6$ & $55.2 \pm 4.4$ \\
\hline & $61-90$ & 107 & $95.3 \pm 3.2$ & $87.5 \pm 4.1$ & $79.4 \pm 4.7$ & $73.8 \pm 5.1$ & $64.8 \pm 5.5$ & $49.0 \pm 6.9$ \\
\hline & $>90$ & 147 & $87.6 \pm 3.3$ & $62.6 \pm 4.3$ & $53.1 \pm 4.4$ & $42.8 \pm 4.3$ & $39.2 \pm 4.3$ & $27.3 \pm 4.3$ \\
\hline \multirow{4}{*}{$\begin{array}{l}\text { Chemotherapy } \\
\text { (chemotherapy } \\
\text { cases) }\end{array}$} & $\leq 30$ & 238 & $68.0 \pm 3.3$ & $52.8 \pm 3.4$ & $43.4 \pm 3.3$ & $40.7 \pm 3.3$ & $38.4 \pm 3.3$ & $33.1 \pm 3.4$ \\
\hline & $31-60$ & 633 & $87.2 \pm 3.4$ & $73.8 \pm 1.8$ & $67.9 \pm 2.0$ & $62.8 \pm 2.0$ & $59.4 \pm 2.1$ & $49.5 \pm 2.5$ \\
\hline & $61-90$ & 382 & $92.3 \pm 1.6$ & $78.8 \pm 2.3$ & $68.9 \pm 2.6$ & $64.5 \pm 2.7$ & $59.8 \pm 2.8$ & $56.1 \pm 3.0$ \\
\hline & $>90$ & 303 & $94.4 \pm 1.7$ & $78.1 \pm 2.6$ & $68.6 \pm 2.9$ & $63.2 \pm 3.0$ & $56.8 \pm 3.1$ & $45.1 \pm 3.9$ \\
\hline \multirow{4}{*}{$\begin{array}{l}\text { Any treatment } \\
\text { (surgiery cases) }\end{array}$} & $\leq 30$ & 1030 & $85.5 \pm 1.1$ & $78.1 \pm 1.3$ & $72.6 \pm 1.4$ & $69.4 \pm 1.5$ & $67.2 \pm 1.6$ & $63.1 \pm 1.8$ \\
\hline & $31-60$ & 428 & $93.4 \pm 1.2$ & $88.8 \pm 1.5$ & $83.8 \pm 1.8$ & $80.5 \pm 2.0$ & $78.0 \pm 2.2$ & $71.5 \pm 2.9$ \\
\hline & $61-90$ & 118 & $94.0 \pm 2.2$ & $85.9 \pm 3.3$ & $79.6 \pm 3.9$ & $74.8 \pm 4.4$ & $71.7 \pm 4.7$ & $56.6 \pm 7.8$ \\
\hline & $>90$ & 99 & $91.7 \pm 2.8$ & $82.2 \pm 3.9$ & $71.9 \pm 4.7$ & $63.9 \pm 5.2$ & $57.1 \pm 5.6$ & $43.8 \pm 8.2$ \\
\hline
\end{tabular}

*Kaplan-Meier product-limit estimate; date of censoring of live cases: 31 December 2012. 
Table 5 Adjusted analysis of HRs (95\% CLs) of deaths from colorectal cancer by time from diagnosis (days) to commencement of specified treatment: South Australians major public hospitals, diagnoses 2000-2010*

\begin{tabular}{|c|c|c|c|c|c|}
\hline \multirow[b]{3}{*}{ Treatment } & \multirow[b]{3}{*}{ Time } & \multicolumn{4}{|c|}{ Follow-up time from diagnoses } \\
\hline & & \multicolumn{2}{|l|}{$\leq 2$ years } & \multicolumn{2}{|l|}{$3-10$ years } \\
\hline & & $\begin{array}{l}\text { Number of } \\
\text { cases }\end{array}$ & HR $(95 \% \mathrm{CL}) \mathrm{s}$ & $\begin{array}{l}\text { Number of } \\
\text { cases }\end{array}$ & HR (95\% CL)s \\
\hline \multirow{4}{*}{$\begin{array}{l}\text { Surgical treatment } \\
\text { (surgery cases) }\end{array}$} & $\leq 30$ & 988 & 1.00 & 714 & 1.00 \\
\hline & $31-60$ & 355 & 0.57 (0.40 to 0.82$)$ & 302 & 0.92 (0.62 to 1.36$)$ \\
\hline & $61-90$ & 100 & 0.59 (0.35 to 1.02$)$ & 76 & 1.13 (0.60 to 2.10$)$ \\
\hline & $>90$ & 232 & 0.59 (0.41 to 0.84$)$ & 186 & 1.24 (0.85 to 1.83$)$ \\
\hline \multirow{4}{*}{$\begin{array}{l}\text { Radiotherapy } \\
\text { (radiotherapy cases) }\end{array}$} & $\leq 30$ & 129 & 1.00 & 87 & 1.00 \\
\hline & $31-60$ & 233 & 0.85 (0.54 to 1.32$)$ & 173 & 1.00 (0.59 to 1.72$)$ \\
\hline & $61-90$ & 107 & 0.44 (0.23 to 0.84$)$ & 89 & 1.26 (0.70 to 2.27$)$ \\
\hline & $>90$ & 147 & 0.62 (0.40 to 0.98$)$ & 89 & 1.60 (0.90 to 2.85$)$ \\
\hline \multirow{4}{*}{$\begin{array}{l}\text { Chemotherapy } \\
\text { (chemotherapy cases) }\end{array}$} & $\leq 30$ & 238 & 1.00 & 120 & 1.00 \\
\hline & $31-60$ & 633 & 0.71 (0.55 to 0.92$)$ & 459 & 0.98 (0.66 to 1.47$)$ \\
\hline & $61-90$ & 382 & 0.51 (0.38 to 0.70$)$ & 289 & 1.01 (0.65 to 1.55$)$ \\
\hline & $>90$ & 303 & 0.40 (0.30 to 0.55$)$ & 233 & 1.04 (0.68 to 1.59$)$ \\
\hline \multirow{4}{*}{$\begin{array}{l}\text { Any treatment } \\
\text { (surgery cases) }\end{array}$} & $\leq 30$ & 1030 & 1.00 & 744 & 1.00 \\
\hline & $31-60$ & 428 & 0.59 (0.43 to 0.81$)$ & 361 & 0.94 (0.66 to 1.33 ) \\
\hline & $61-90$ & 118 & 0.48 (0.43 to 0.81$)$ & 95 & 1.11 (0.66 to 1.89$)$ \\
\hline & $>90$ & 99 & $0.62(0.37$ to 1.02$)$ & 78 & $1.83(1.12$ to 2.98$)$ \\
\hline
\end{tabular}

*Four Cox proportional hazards regression analyses (one per treatment category), adjusting for age, sex, socioeconomic status, service accessibility, local health network, subsite, stage, grade and diagnostic period (tables 2 and 3); date of censoring of live cases: 31 December 2012.

$\mathrm{CL}$, confidence limit.

by 10 years from diagnosis, survival was lower when time to initial surgery was $>90$ days compared with $\leq 30$ days $(\mathrm{p}=0.021)$.

\section{Adjusted analysis}

Results are presented in table 5 .

Because visual examination and interaction terms indicated a lack of proportionality of survival with time to treatment, results are split in table 5 for follow-up of $\leq 2$ and 3-10 years as mutually exclusive periods. Irrespective of treatment type, lower HRs applied for periods $\leq 2$ years with times to treatment of $>30$ days, after adjusting for age, sex, socioeconomic status, service accessibility, local health network of residence, tumour subsite, stage, grade and diagnostic period. HRs similarly adjusted generally did not decrease across the 3-10 years follow-up, suggesting no significant differences in conditional survival after 2 years for cases treated $\leq 30$ days of diagnosis and $>30$ days. While there were higher HRs for times of 61-90 and $>90$ days for 3-10years follow-up from surgical treatment and radiotherapy respectively, statistical significance was only achieved for any treatment (surgical cases) when comparing time to treatment $>90$ with $\leq 30$ days $(\mathrm{p}=0.022)$.

\section{DISCUSSION}

The proportion of surgical patients receiving any treatment for their cancer $\leq 60$ days of diagnosis was $87 \%$, with $80 \%$ receiving surgical treatment within 60 days of diagnosis. This broadly accords with targets set by Cancer UK. ${ }^{9}$ The proportion receiving radiotherapy who started this therapy $\leq 60$ days of diagnosis was $59 \%$, whereas the corresponding percentage having chemotherapies who started this therapy $\leq 60$ days of diagnosis was $56 \%$. The longer delay for radiotherapy and chemotherapy is consistent with their common use as adjuvant therapies following surgery. ${ }^{5}$

Longer time to surgery applied for cancers of the rectum than colon potentially reflecting the increased use of MRI for rectal cancers, ${ }^{25}$ and multimodal therapies, ${ }^{5}$ which may have led to surgery delays through more multidisciplinary consultation and in some instances, neoadjuvant care. ${ }^{26}$

The longer time to surgery in 2006-2010 may also have been influenced by increasing use of multimodal therapies and more advanced diagnostics (eg, MRI), increasing the need for multidisciplinary consultation. ${ }^{5} 26$ While the introduction of population-based screening may have contributed, the screening programme was still at an early phase of development, being phased in from 2006 to 2020 . Following more complete implementation of bowel screening, there may be increased pressure on services which may increase times to surgery. ${ }^{78}$ The higher proportion with a time to surgery $>60$ days for stages $\mathrm{C}$ and $\mathrm{D}$ compared with stage A may reflect 
time taken for symptom control, multidisciplinary team consultation and provision of neoadjuvant therapies. ${ }^{27} 28$ The proportion with a time to surgery $>60$ days was lower for higher grade tumours, potentially due to a greater perceived urgency of surgical intervention for more aggressive tumours.

The proportion receiving surgery, who did so $>60$ days from diagnosis, tended to be lower among those aged 70+ years, central and southern compared with northern metropolitan areas, those diagnosed in 20002005 compared with 2006-2010 and unexpectedly, those residing closer to metropolitan services. The reasons are unclear but may reflect differences in service busyness and patterns of patient and service demand.

Of those receiving radiotherapy, the proportion starting this therapy $>60$ days from diagnosis tended to be higher for ages $\geq 60$ years than for ages $<50$ years. A similar pattern applied for chemotherapy. The reasons are not known. Perhaps a longer recovery time postsurgery has been allowed for older cases postsurgery before commencing adjuvant therapies, or longer delays occurring due to higher levels of frailty and comorbidity, and more common complications of surgery.

Radiotherapy was relatively uncommon for colon cancers, as recommended in clinical guidelines and optimal care pathways, ${ }^{27} 28$ but when it was provided, it tended to start later than for rectal cases. Similarly, chemotherapies tended to commence later for colon than rectal cancers. Further research is needed to determine the reasons for these patterns. Chemotherapies were less likely to commence $>30$ days from diagnosis for 2006-2010 diagnoses. Conversely, chemotherapies were more inclined to occur $>60$ days from diagnosis in 2006-2010. Again, further research is needed to explain these patterns.

Where the time from diagnosis to treatment was $>30$ days, the risk of death occurring $\leq 2$ years of diagnosis was lower. This was evident by therapy type after adjusting for stage and grade, and sociodemographic factors. It may reflect the triaging for priority treatment $\leq 30$ days for cases with elevated comorbidity or other risk factors not recorded by the registry. While a statistically significant U-shaped relationship of survival with time to treatment start was usually not apparent for specific therapies, as indicated in some other studies, ${ }^{617}$ the HR for 3-10 years was elevated when the time to first treatment was $>90$ days for surgical cases $(\mathrm{p}=0.022)$.

The present study has limitations. An opportunistic approach was taken in selecting cases where evidence was available on size of the gap between recorded diagnosis date and start of treatment. This raises questions about the representativeness of results. Nonetheless, results are similar to those of other recent studies in showing poorer short-term survival for cases receiving surgical treatment soon after diagnosis, and with a similar pattern applying for early treatment by radiotherapy and chemotherapies. $^{12} 141517$

Results should not be construed as indicating a lack of benefit from early treatment, given likely confounding effects of patient selection in treatment scheduling. A positive feature was the approximate $87 \%$ of surgical cases receiving their first treatment (any treatment) $\leq 60$ days and $80 \%$ treated surgically within this period (note: $83 \%$ for $2000-2005$ and $78 \%$ for $2006-2010$ ). ${ }^{9}$ The indication of a temporal decline in this percentage warrants continued monitoring and investigation, particularly for patient groups where a higher proportion was not receiving surgical care $\leq 60$ days of diagnosis (eg, patients aged $<50$ years, those with advanced disease, those with rectal cancer and residents of the northern metropolitan rather than central or southern metropolitan areas).

The study highlights the benefit of linking diagnostic data to treatment data. Population-wide data linkage of population-based cancer registry, hospital, radiotherapy centre, Medicare insurance and screening data and potentially in the future, electronic medical record data and selected research databases will further strengthen the data infrastructure available for describing clinical management pathways and associations with survival across the population. Clinical registries will still be important for more detailed investigations for the subgroups they cover, and for validating results of population-wide registry and administrative sources.

\section{CONCLUSIONS}

Baseline data for major public hospitals in South Australia in 2000-2010 indicate that for cases where the clinical registry recorded a diagnosis in advance of the surgery date, approximately $87 \%$ of surgical cases receiving any treatment and $80 \%$ of cases received their surgical treatment $\leq 60$ days of diagnosis. This is broadly consistent with timeline targets of Cancer UK. Radiotherapy and chemotherapies generally started later, potentially reflecting their use as adjuvant therapies.

Adjusted analyses indicated lower survival up to 2 years from diagnosis when treatment commenced $\leq 30$ days of diagnosis, potentially reflecting triaging for early care of cases with aggressive cancers and higher clinical complexity. By comparison, adjusted analyses did not show differences in survival for follow-up periods from diagnosis of 3-10 years where longer times to treatment applied, except for time to any treatment (surgical cases) of $>90$ days when survival was lower.

These results should not be interpreted as evidence of the importance or unimportance of delays, given selection factors in scheduling patient care. Treatment commencement was generally later in 2006-2010 than 2000-2005, possibly reflecting increased use of adjuvant therapies, increased use of multidisciplinary teams and more advanced diagnostics (eg, MRI). Increased demand may be placed on timeliness of clinical services with extensions in population screening.

Further research is needed to optimise patient scheduling for better outcomes. 
Author affiliations

${ }^{1}$ Cancer Research Institute, University of South Australia, Adelaide, South Australia, Australia

${ }^{2}$ Medical Oncology, Flinders University, Adelaide, South Australia, Australia

${ }^{3}$ South Australian Cancer Service, South Australia Department of Health, Adelaide, South Australia, Australia

${ }^{4}$ Adelaide Medical School, The University of Adelaide, Adelaide, South Australia, Australia

${ }^{5}$ Surgery and Perioperative Medicine, Southern Adelaide Local Health Network, Bedford Park, South Australia, Australia

${ }^{6}$ Colorectal Surgery, Royal Adelaide Hospital, Adelaide, South Australia, Australia ${ }^{7}$ Cancer Research and Clinical Trials, Adelaide Oncology and Haematology, North Adelaide, South Australlia, Australia

${ }^{8}$ Gastrointestinal Cancer Biology, South Australian Health and Medical Research Institute, Adelaide, South Australia, Australia

${ }^{9}$ Population Health, South Australian Health and Medical Research Institute, Adelaide, South Australia, Australia

${ }^{10}$ School of Public Health, The University of Adelaide, Adelaide, South Australia, Australia

${ }^{11}$ Clinical Cancer Research, The Queen Elizabeth Hospital, Woodville South, South Australia, Australia

Contributors Study concept: DR, TP; study design: DR TP, CSK, RP, JM; data acquisition: DB-T, KP; quality control of data: DB-T, KP, KF; data analysis: DR, KF; data interpretation: DR, CSK, IO, DK, RP, JM, RJ, DW, DLW, TP; report writing: DR, KF review of report: DR, CSK, IO, DK, RP, JM, RJ, DW, DLW, TP, CLM, CH, EB. All authors read and approved the final manuscript.

Funding This study was undertaken with the financial support of Cancer Council's Beast Cancer Project on behalf of its donors and the State Government through the Department of Health.

Competing interests DR reports grants from Cancer Council SA, during the conduct of the study.

Patient consent for publication Not required.

Ethics approval Research ethics approval was obtained from the South Australian Human Research Ethics Committee (HREC/14/SAH/145) and University of South Australia Research Ethics Committee.

Provenance and peer review Not commissioned; externally peer reviewed.

Data availability statement Data may be obtained from a third party and are not publicly available.

Open access This is an open access article distributed in accordance with the Creative Commons Attribution Non Commercial (CC BY-NC 4.0) license, which permits others to distribute, remix, adapt, build upon this work non-commercially, and license their derivative works on different terms, provided the original work is properly cited, appropriate credit is given, any changes made indicated, and the use is non-commercial. See: http://creativecommons.org/licenses/by-nc/4.0/.

\section{ORCID iDs}

David Roder http://orcid.org/0000-0001-6442-4409

Caroline Louise Miller http://orcid.org/0000-0001-9723-8047

Carol Holden http://orcid.org/0000-0002-4011-6628

\section{REFERENCES}

1. Ferlay J, Ervik M, Lam F, et al. Global cancer Observatory: cancer today. France: international agency for research on cancer, 2018. Available: https://gco.iarc.fr/today [Accessed 28 Sep 2018].

2. Australian Institute of Health and Welfare (AlHW) 2018 Cancer Data in Australia. Australian cancer incidence and mortality (ACIM) books: all cancers combined, Canberra: AlHW, 2018. Available: https://www. aihw.gov.au/reports/cancer/cancer-data-in-australia/ [Accessed 23 Jan 2019].

3. Australian Institute of Health and Welfare (AlHW). Cancer data in Australia. Cat. no: CAN 122. Canberra, 2018. Available: https:// www.aihw.gov.au/reports/cancer/cancer-data-in-australia/contents/ summary [Accessed 23 Jan 2019].
4. Australian Government, Australian Institute of Health and Welfare, Australasian Association of Cancer Registries. Cancer survival and prevalence in Australia: cancers diagnosed from 1982 to 2004. cancer series No. 42. Cat. No. CAN 38. Canberra AlHW; 2008.

5. Roder D, Karapetis CS, Wattchow D, et al. Colorectal cancer treatment and survival: the experience of major public hospitals in South Australia over three decades. Asian Pac J Cancer Prev 2015;16:2431-40.

6. Singh $\mathrm{H}, \mathrm{De}$ Coster $\mathrm{C}$, Shu $\mathrm{E}$, et al. Wait times from presentation to treatment for colorectal cancer: a population-based study. Can $J$ Gastroenterol 2010;24:33-9.

7. Hanna SJ, Muneer A, Khalil KH. The 2-week wait for suspected cancer: time for a rethink? Int J Clin Pract 2005;59:1334-9.

8. Roncoroni L, Pietra N, Violi V, et al. Delay in the diagnosis and outcome of colorectal cancer: a prospective study. Eur J Surg Oncol 1999;25:173-8.

9. Cancer Research UK. Cancer waiting times. London Cancer Research UK; 2018. https://www.cancerresearchuk.org/aboutcancer/cancer-in-general/treatment/access-to-treatment/waitingtimes-after-diagnosis

10. Barillari $\mathrm{P}$, de Angelis $\mathrm{R}$, Valabrega $\mathrm{S}$, et al. Relationship of symptom duration and survival in patients with colorectal carcinoma. Eur $\mathrm{J}$ Surg Oncol 1989;15:441-5.

11. Gonzalez-Hermoso F, Perez-Palma J, Marchena-Gomez J, et al. Can early diagnosis of symptomatic colorectal cancer improve the prognosis? World J Surg 2004;28:716-20.

12. Rupassara KS, Ponnusamy S, Withanage N, et al. A paradox explained? patients with delayed diagnosis of symptomatic colorectal cancer have good prognosis. Colorect Dis 2006;8:423-9.

13. Jullumstrø E, Lydersen S, Møller B, et al. Duration of symptoms, stage at diagnosis and relative survival in colon and rectal cancer. Eur J Cancer 2009;45:2383-90.

14. Pruitt SL, Harzke AJ, Davidson NO, et al. Do diagnostic and treatment delays for colorectal cancer increase risk of death? Cancer Causes Control 2013;24:961-77.

15. Amri R, Bordeianou LG, Sylla P, et al. Treatment delay in surgicallytreated colon cancer: does it affect outcomes? Ann Surg Oncol 2014;21:3909-16.

16. Young CG, Varghese R, Stephens $\mathrm{JH}$, et al. Colorectal cancer survival is not affected by delay in diagnosis. Clin Surg 2016;1.

17. Pita-Fernández S, González-Sáez L, López-Calviño B, et al. Effect of diagnostic delay on survival in patients with colorectal cancer: a retrospective cohort study. BMC Cancer 2016;16:664.

18. Wanis KN, Patel SVB, Brackstone M. Do moderate surgical treatment delays influence survival in colon cancer? Dis Colon Rectum 2017;60:1241-9.

19. Okuyama A, Shibata A, Nishimoto H. Critical points for interpreting patients' survival rate using cancer registries: a literature review. $J$ Epidemiol 2018;28:61-6.

20. Commission on Cancer. FORDS: facility oncology registry data standards: revised for 2016. Chicago, IL American College of Surgeons; 2016.

21. Davis NC, Newland RC. Terminology and classification of colorectal adenocarcinoma: the Australian clinico-pathological staging system. ANZ J Surg 1983;53:211-21.

22. Australian Bureau of Statistics. Socio-Economic indexes for areas. Canberra ABS; 2018.

23. Armitage P, Berry G. Statistical methods in medical research. Blackwell Scientific Publications: Oxford, 1987.

24. Statistical Analysis System. The SAS platform: SAS enterprise guide 7.1. SAS: Cary NC, 2018.

25. Jhaveri KS, Hosseini-Nik H. MRI of rectal cancer: an overview and update on recent advances. AJR Am J Roentgenol 2015;205:W42-W55.

26. Cancer Council NSW. Bowel cancer. your health care team. Sydney: cancer Council, 2017. Available: https://www.cancercouncil.com. au/bowel-cancer/diagnosis/health-professionals/ [Accessed 28 Sep 2018].

27. Cancer Council Australia Colorectal Cancer Guidelines Working Party. Clinical practice guidelines for the prevention, early detection and management of colorectal cancer. Sydney: Cancer Council Australia. Available: https://wiki.cancer.org.au/australia/Guidelines: Colorectal_cancer [Accessed 1 Jan 2018].

28. National Cancer Expert Reference Group (NCERG). Optimal care pathway for people with colorectal cancer. Sydney: Cancer Council Australia, 2016. Available: https://www.cancer.org.au/healthprofessionals/optimal-cancer-care-pathways.html [Accessed $28 \mathrm{Sep}$ 2018]. 